\title{
TOTAL KNEE ARTHROPLASTY IN HAEMOPHILIC ARTHRITIS
}

\author{
M. SMAll, M. M. STeven, P. A. Freeman, G. D. O. LOWE, J. J. F. BelCh, C. D. Forbes, C. R. M. PRENTICE
}

From the Glasgow Royal Infirmary, the Centre for Rheumatic Diseasés, and the Victoria Infirmary, Glasgow

\begin{abstract}
The results of total knee replacement in five patients aged between 22 and 37 with severe haemophilia $A$ or B are described. All patients had been managed conservatively without success. Frequent bleeds, severe pain and limitation of movement were the indications for operation. Despite close haematological surveillance, bleeding problems occurred in three of the patients and large quantities of plasma concentrates were required. Review of the patients over a period of 25 to $\mathbf{4 8}$ months after operation showed dramatic lessening of pain and maintenance of a satisfactory range of movement. The frequency of haemarthrosis diminished markedly and the requirements for factor concentrate in the years after operation fell substantially. Two patients returned to employment. Total knee replacement led to marked clinical improvement in all the patients, but the longterm results are not yet known.
\end{abstract}

The most common clinical manifestation of haemophilia is musculoskeletal bleeding, and haemarthrosis leading to chronic arthropathy is the most disabling feature of the disease. As clotting factor concentrates have become more readily available, special centres have been established where outpatient treatment for haemarthrosis and other bleeds is readily available. More recently home therapy has allowed an increasing number of patients to treat episodes of bleeding early, and reduce the number of bleeds. Increasing availability of factor concentrates has also permitted elective operations, including orthopaedic procedures, to be carried out (Arnold and Hilgartner 1977). Synovectomies have been successful in reducing the frequency of episodes of bleeding in cases where haemostatic measures have been ineffective (Pietrogrande, Dioguardi and Mannucci 1972; Storti and Ascari 1975) and a number of soft-tissue procedures to correct deformity have been devised (Arnold and Hilgartner 1977; Houghton 1981). Total hip arthroplasty for advanced disease has also been successfully carried out, but the knee, which is the commonest site of haemarthrosis and of chronic haemophilic arthropathy, has only been the subject of prosthetic replacement on a few occasions (Post and Telfer 1975; Arnold and Hilgartner 1977; London et al. 1977; Marmor 1977;

M. Small, MB, MRCP, Registrar

J. J. F. Belch, MB, MRCP, Honorary Registrar

G. D. O. Lowe, MB, MRCP, Lecturer

C. D. Forbes, MD, FRCP, Senior Lecturer

C. R. M. Prentice, MD, FRCP, Reader in Medicine

University Department of Medicine, Glasgow Royal Infirmary,

Glasgow G4 0SF, Scotland.

M. M. Steven, MB, MRCP, Senior Registrar

The Centre for Rheumatic Diseases, Baird Street, Glasgow G4 0EH, Scotland.

P. A. Freeman, MB, FRCS, Consultant Orthopaedic Surgeon

Department of Orthopaedics, Victoria Infirmary, Glasgow G42 9TY,

Scotland.

Requests for reprints should be sent to Dr M. Small.

(C) 1983 British Editorial Society of Bone and Joint Surgery $0301-620 \mathrm{X} / 83 / 2037-0163 \$ 2.00$
McCollough et al. 1979; Goldberg et al. 1981; Luck 1981). To our knowledge no previous cases have been reported from centres in the United Kingdom. We report here five cases of total knee replacement using the Geomedic prosthesis carried out at a single centre between 1977 and 1979.

\section{PATIENTS AND METHOD}

Four patients with severe haemophilia $A$ and one with severe haemophilia $B$ who had factor levels of less than one unit per decilitre had chronic arthropathy of the knee which had failed to respond to conservative therapy. All patients had suffered recurrent haemarthroses resulting in a chronically painful joint with a limited range of movement which led to prolonged absences from work. Conservative measures which had been tried, without benefit, included a period of prophylactic home therapy, analgesics, non-steroidal anti-inflammatory drugs and physiotherapy. Radiographs of all patients showed severe destructive changes (Stages IV and V: Arnold and Hilgartner 1977) and total replacement of the knee was decided to be the optimal treatment. All patients were screened to exclude coagulation inhibitors and hepatitis Type B. One hour before the operation patients were given a dose of factor concentrate estimated to raise the levels of factor VIII or IX to over 80 per cent; blood samples were collected before and 15 minutes after operation and assayed for factor VIII and IX. The first two patients received plasma concentrate thrice daily for the first few days after operation, but experience from these cases revealed that twice daily infusions were sufficient. Using this regime all patients had haemostatic factor levels of greater than 80 per cent before operation and the levels were maintained at over 50 per cent for four days. For the remainder of the stay in hospital, factor replacement was given in a dose calculated to maintain plasma levels of 30 per cent. The fibrinolytic inhibitor, tranexamic acid, was given to Cases 3 and 4 . A variety of commercial concentrates and blood transfusion concentrates was used in all patients. The patient with haemophilia B was given Edinburgh PFC Factor IX concentrate (DEF IX).

\section{SURGICAL PROCEDURE}

Insertion of a Geomedic total knee replacement was carried out in a standard fashion using a pneumatic tourniquet and dissection by scalpel and electrocautery. A limited synovectomy was simultaneously carried out. Dexon sutures were used and a negative pressure drain inserted for $\mathbf{4 8}$ hours. The leg was enclosed in a Robert Jones' type bandage and immediately after operation static quadriceps exercises 
Table I. Results of total knee replacement in five haemophiliacs

\begin{tabular}{|lllllcl|}
\hline Case & $\begin{array}{l}\text { Age } \\
\text { (years) }\end{array}$ & $\begin{array}{l}\text { Stay in hospital } \\
\text { (days) }\end{array}$ & Knee replaced & Before operation & After operation & $\begin{array}{l}\text { Follow-up } \\
\text { (months) }\end{array}$ \\
\hline 1 & 27 & 38 & Right & 10 to 80 & 0 to 90 & 48 \\
2 & 35 & 30 & Right & 20 to 90 & 0 to 80 & 48 \\
3 & 22 & $24+7+15^{*}$ & Left & 5 to 90 & 0 to 70 & 29 \\
4 & 27 & 75 & Right & 10 to 25 & 0 to 70 & 29 \\
5 & 37 & $8^{*}$ & Left & 15 to 90 & 25 to 75 & 25 \\
\hline
\end{tabular}

* Irregular discharge from hospital

were started. Partial weight-bearing was begun at four or five days and fuller mobilisation was instituted after the sutures had been removed at approximately 14 days. Daily physiotherapy was carried out after infusion of plasma concentrates and appropriate analgesia.

\section{RESULTS}

The details of the patients and their range of knee movement after prosthetic replacement are shown in Table I. All patients had total relief or dramatic lessening of pain after total knee replacement and three (Cases 1, 2 and 4) eventually achieved an improved range of movement. Two of the three patients who had been in full-time employment before operation, but who had had prolonged periods of absence, returned to work successfully. Compliance with physiotherapy was poor in three patients. Case 5 required two manipulations under general anaesthesia, but despite this he regained only a limited range of movement. After operation this patient complained of pain along the sciatic nerve but he had no neurological deficit. The pain persisted throughout the period of follow-up and although his knee was free of pain and seldom bled, the outcome was regarded as poor. He had discharged himself from hospital early in the postoperative period and had failed to attend physiotherapy sessions as an outpatient.

In four patients haemarthrosis of the operated joint was abolished or markedly reduced in the years after operation, as indicated by their reduced requirement for plasma concentrates (Table II). The amount of concentrate used in the first postoperative year was high due to the administration of prophylactic concentrate before

Table II. Concentrate requirement before and after total knee replacement (units $\times 10^{3}$ )

\begin{tabular}{|lclllll|}
\hline \multirow{2}{*}{$\begin{array}{l}\text { Year } \\
\text { Case } \\
\text { before } \\
\text { operation }\end{array}$} & $\begin{array}{l}\text { During } \\
\text { period of }\end{array}$ & \multicolumn{4}{l}{ After operation } \\
\cline { 4 - 7 } & operation & Ist year & 2nd year & 3rd year & 4th year \\
\hline $1^{*}$ & 32 & 155 & 55 & 29 & 11 & 3 \\
2 & 5 & 99 & 14 & 7 & 0 & 4 \\
3 & 65 & 64 & 70 & 4 & - & - \\
4 & 147 & 87 & 63 & 60 & - & - \\
5 & 9 & 27 & 60 & 3 & - & - \\
\hline
\end{tabular}

* Haemophilia B physiotherapy. One patient (Case 4) continued to use large amounts of concentrate for bleeds into the operated joint although there were no objective signs of bleeding. One patient developed a superficial wound infection which lengthened his stay in hospital but the infection responded to antibiotics. One other patient developed a pyrexia and was given antibiotics, although bacteriological examinations were subsequently negative. The average stay in hospital was 40 days. No patient developed clinical or laboratory evidence of hepatitis and none developed an inhibitor to factor VIII or IX.

Bleeding complications. In all patients moderate perioperative blood loss occurred which required replacement with one to three units of whole blood. This is comparable with the loss of blood in patients with rheumatoid arthritis undergoing total knee replacement.

Case 1, who had haemophilia B, required three units of blood. Three days after operation he developed disseminated intravascular coagulation and required a further two units of blood and large doses of fibrinogen in the form of cryoprecipitate. Administration of factor IX was thereafter decreased and he subsequently developed a retroperitoneal bleed while being mobilised.

Case 3 was readmitted to hospital on two occasions (having taken irregular discharge previously) with bleeds into the prosthetic joint but these were easily controlled by infusion of plasma concentrates. Despite haemostatic levels of factor VIII, Case 4 sustained a large bleed into the prosthetic joint which also responded to further replacement of concentrates.

\section{DISCUSSION}

Chronic destructive arthropathy is common in adult haemophiliacs and affects as many as 60 per cent of those with severe haemophilia (Ali et al. 1967). Despite marked radiographical changes, function may remain satisfactory and orthopaedic intervention is rarely indicated. Patients with recurrent bleeds which do not respond to a period of immobilisation and intensive replacement of factor concentrate (Arnold and Hilgartner 1977) may benefit from synovectomy (Storti and Ascari 1975) but if pain is prominent and radiographical changes are marked, this may not be adequate and arthrodesis has 
been recommended (Houghton 1981). However, arthrodesis leaves the patient with a marked degree of disability, and total knee replacement, which can relieve pain, reduce bleeding and provide the patient with a useful range of movement, has been advocated (Post and Telfer 1975; Marmor 1977; McCollough et al. 1979; Goldberg et al. 1981; Luck 1981). Several small series have been reported from North American centres with the conclusion that the procedure was beneficial, although complications were frequent and included skin necrosis, nerve palsies (Goldberg et al. 1981), serious wound infection (McCollough et al. 1979; Goldberg et al. 1981), reduced range of joint movement (Luck 1981; McCollough et al. 1979), and loosening of the prosthesis necessitating revision operations in five cases (McCollough et al. 1979; Goldberg et al. 1981; Luck 1981). Other complications have included bleeding into the prosthetic joint (McCollough et al. 1979; Goldberg et al. 1981; Luck 1981) and we observed an episode of disseminated intravascular coagulation in a patient with factor IX deficiency which is a recognised complication of infusion of high doses of factor IX (Kasper 1975). Case 1 is discussed in detail elsewhere (Small et al. 1982).

Despite worries about the duration of the effectiveness of total knee replacement and the added danger of sepsis in haemophiliacs, surface replacement with the Geomedic prosthesis dramatically reduced pain and improved mobility in our patients. The improvement in the quality of life at a time of maximal involvement in work and family life was impressive. The minimal amount of bone removed at operation allowed the possibility of revision procedures as and when deterioration of the prosthetic joint necessitated it. Although slight flexion contractures and valgus deformities could be corrected, the overall range of movement was unlikely to be greater than before operation and the operation should be considered before severe deformity occurs. Emphasis should be placed on physiotherapy after operation with adequate concentrate replacement and administration of analgesics.

The necessity for an experienced orthopaedic surgeon to be working in collaboration with physicians able to supervise the factor replacement, and supported by a coagulation laboratory, the blood transfusion service and physiotherapists will limit the number of centres where such procedures can be performed. In addition, the average cost of factor concentrates at $£ 8000$ per operation makes this an expensive form of treatment. The subsequent reduction in requirement of concentrates (Table II) can be offset against this cost, but the reduction in pain and disability with improvement in the quality of life cannot be costed. Despite the fears for the durability of total knee replacement, the cost and the high rate of complications, we feel this procedure could be of benefit to a few selected patients with crippling arthritis due to coagulation abnormalities.

We hope that in the future prevention of chronic arthropathy in haemophiliacs can be achieved by an expansion of the home treatment programme and solimit or avoid the requirement for orthopaedic surgery.

We wish to thank Dr J. F. Davidson for his help with the provision of the factor concentrates used during these operations.

\section{RFFERENCES}

Ali AM, Gandy RH, Britten MI, Dormandy KM. Joint haemorrhage in haemophilia: is full advantage taken of plasma therapy? Br Med J 1967:iii : 828-31.

Arnold WD, Hilgartner MW. Hemophilic arthropathy: current concepts of pathogenesis and management. J Bone Joint Surg [Am] 1977: 59-A : 287-305.

Goldberg VM, Heiple KG, Ratnoff OD, Kurczynski E, Arvan G. Total knee arthroplasty in classic hemophilia. J Bone Joint Surg [Am] 1981: 63-A : 695-701.

Houghton GR. Joint surgery in haemophilia. In: Lowe GDO. Forbes CD, eds. Unresolved problems in haemophilia. Lancaster: MTP Press Ltd, $1981: 217-32$.

Kasper CK. Thromboembolic complications. Thromb Diath Haemorrh 1975:33:640-4.

London JT, Kattlove H, Louie JS, Forster GL. Synovectomy and total knee arthroplasty for recurrent hemarthroses in the arthropathic joint in hemophilia. Arthritis Rheum 1977;20:1543-5.

Luck JV Jr. Prosthetic knee arthroplasty for advanced haemophilic arthropathy: preliminary report. In: Seligsohn U, Rimon A, Horoszowski H. eds. Haemophilia. Tunbridge Wells: Castle House Publications, 1981:183-7.

McCollough NC III, Enis JE, Lovitt J, Lian EC-Y, Niemann KNW, Loughlin EC Jr. Synovectomy or total knee replacement of the knee in hemophilia. J Bone Joint Surg [Am] 1979:61-A:69-75.

Marmor L. Total knee replacement in hemophilia. Clin Orthop 1977:125:192-5.

Pietrogrande V, Dioguardi N, Mannucci PM. Short-term evaluation of synovectomy in haemophilia. Br Med J 1972:ii:378-81.

Post M, Telfer MC. Surgery in hemophilic patients. J Bone Joint Surg [Am] 1975:57-A : 1136-45.

Small M, Lowe GDO, Douglas JT, Forbes CD, Prentice CRM. Factor IX thrombogenicity: in civo effects on coagulation activation and a case report of disseminated intravascular coagulation. Thromb Haemostas 1982:48:76-7.

Storti E, Ascari E. Surgical and chemical synovectomy. Ann NY Acad Sci 1975;240:316-7. 